\title{
The Kidney Model as an Inverse Problem
}

M. Breinbauer

Mathematische Analysen und Systeme GmbH (MAS)

Konrad-Adenauer-Allee 30

D-8400 Regensburg, West Germany

and

P. Lory

Mathematisches Institut

Technische Universität München

Postfach 202420

D-8000 München 2, West Germany

Transmitted by Melvin R. Scott

\section{ABSTRACT}

The mammalian kidney is modeled by a multipoint boundary-value problem for a system of nonlinear ordinary differential equations. A corresponding inverse problem is presented, which allows the rigorous judgement of the potential of the given modeling technique. For its numerical solution a discretization is proposed, which is tailor-made for kidney models. It leads to a nonlinear-programming problem with nonlinear equality and inequality constraints. The suggested methods are applied to current research problems in renal physiology.

\section{INTRODUCTION}

During the last two decades mathematical kidney models of increasing complexity have become an indispensable tool in the effort towards a complete understanding of hypertonic urine formation. Hypotheses on the renal concentrating mechanism cannot be judged by purely experimental results. They must pass a test in the form of a mathematical simulation based on principles of local mass balance. In the case of steady-state simulations, 
these principles lead to a boundary-value problem for a system of nonlinear ordinary differential equations.

Naturally, this boundary-value problem depends on many geometric and thermodynamic parameters, like solute permeabilities of the membranes in the various tubular segments. Because of their biological nature, most of these data can be measured only with considerable uncertainty.

A completely satisfactory kidney model must meet two requirements: First, it must use parameters within their ranges of measurements. Second, the model must predict steep concentration gradients in the inner medulla in accord with tissue-slice experiments. This requirement is the bottleneck for present-day kidney models [1]. As a consequence, it is absolutely essential to know which values of the parameters (within their ranges of uncertainty) predict the strongest increase of inner medullary concentration. This is the inverse problem, which is studied in the present paper. Commonly this task has been attacked by a mixture of heuristic arguments and trial-and-error strategies.

The present paper suggests a more systematic approach: The boundaryvalue problem is discretized in a semidiscrete manner. Thus, the original inverse problem is reduced to a nonlinear optimization problem with 100 independent variables, 84 nonlinear equality constraints, and 38 inequality constraints. This can be solved effectively by the sequential quadratic programming method.

Besides the physiological insights that can be gained by this approach, the arising nonlinear optimization problem may also be of interest as a test problem for optimization software.

The paper is structured as follows: The boundary-value problem modeling the kidney is formulated in Section 2. The inverse problem and its numerical solution are presented in Section 3. Section 4 applies these techniques to current research in renal physiology. The consequences of these results are commented in the concluding remarks of Section 5.

\section{THE BOUNDARY-VALUE PROBLEM MODELING THE RENAL CONCENTRATING MECHANISM}

The mammalian kidney consists of thousands of similar functional units, called nephrons. A schematic diagram of a single nephron forming a countercurrent system is given in Figure 1. Fluid flows in sequence through the descending and the ascending limb of Henle's loop (DLH and ALH), the distal tubule (DT), and the collecting duct (CD). At its end the fluid emerges into the pelvis. All the nephrons are embedded in a common compartment, called the central core $(\mathrm{CC}$; see $[2,3])$.

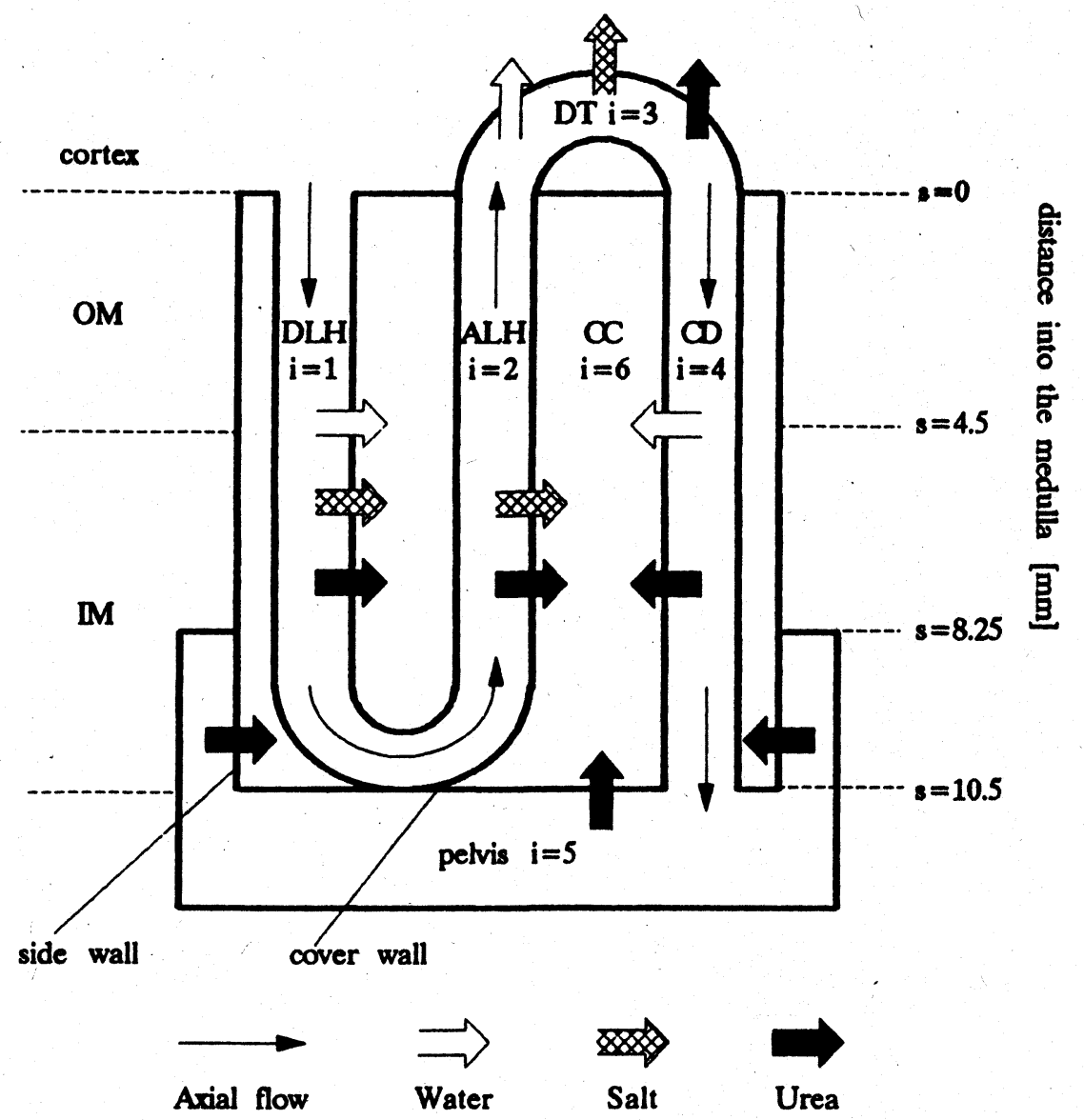

Fic. 1. Schematic diagram of a single long nephron. The indicated orientations of the arrows correspond to positive fluxes. DLH (ALH), descending (ascending) limb of Henle's loop: DT, distal tubule; CD, collecting duct; CC, central core; OM (IM), outer (inner) medulla.

Two solutes are present in the model: salt $(l=1)$ and urea $(l=2)$. Exchange between the nephron segments occurs through solute and water movement in the central core. The diagram reflects the impermeability of the ALH to water and the impermeability of the CD to salt (cf. the discussion in [4]). In addition, Figure 1 defines a numbering of the various segments.

The loops of Henle extend to varying depths within the renal medulla. In order to model the architecture of this tubular system (which is described in [5]), the inner medulla is subdivided into three parts (Figure 2). The number 


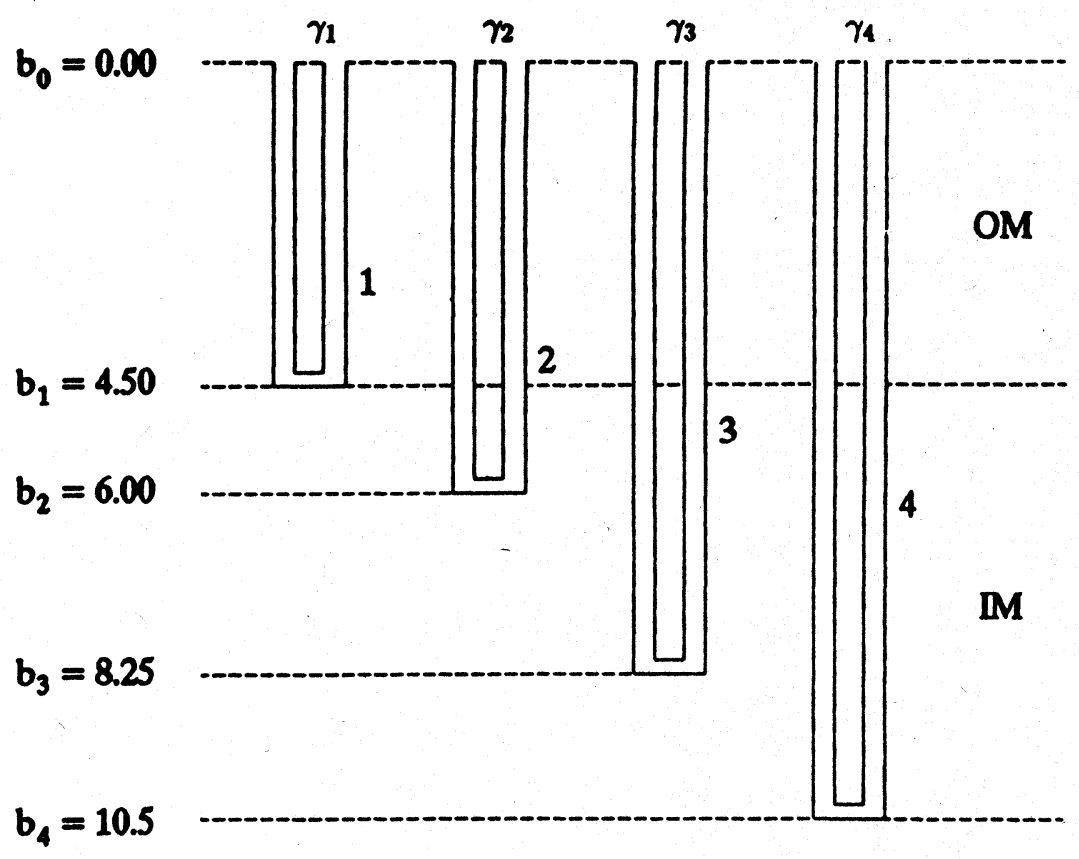

Fic. 2. Distribution of the 1536 loops of Henle. OM (IM), outer (inner) medulla.

of loops of length $b_{j}$ is given by $\gamma_{j}$. Altogether, 1536 loops are present in the model. This number is chosen because 1536 loops eventually merge into one CD. As a consequence,

$$
\gamma_{1}+\gamma_{2}+\gamma_{3}+\gamma_{4}=1536
$$

The following paragraph describes the modeling of the DLH of length $b_{j}$ : Let $F_{1 v}^{j}$ and $F_{1 l}^{j}$ denote the axial volume flow rate and the axial flow rate of solute $l$ in this tubular segment, $r_{1}$ its radius, and $s$ the distance into the medulla from the corticomedullary border. The following system of differential equations results from the requirement of local mass balance:

$$
\begin{aligned}
& \frac{d F_{1 v}^{j}}{d s}=-2 \pi r_{1} \cdot J_{1 v}^{j}, \quad j=1, \ldots, 4, \\
& \frac{d F_{1 l}^{j}}{d s}=-2 \pi r_{1} \cdot J_{1 l}^{j}, \quad l=1,2, \quad j=1, \ldots, 4 .
\end{aligned}
$$

According to the laws of irreversible thermodynamics (see [6]) the transmural fluxes are given by

$$
\begin{aligned}
& J_{1 v}^{j}=\operatorname{Lp}_{1}\left[1.82 \sigma_{11}\left(C_{61}-C_{11}^{j}\right)+\sigma_{12}\left(C_{62}-C_{12}^{j}\right)\right] \\
& J_{1 l}^{j}=P_{1 l} \cdot\left(C_{1 l}^{j}-C_{6 l}\right)+\left(1-\sigma_{1 l}\right) J_{1 v}^{j} \bar{C}_{1 l}^{j},
\end{aligned}
$$

where $\bar{C}_{1 l}^{j}:=\left(C_{1 l}^{j}+C_{6 l}\right) / 2$. The concentration of solute $l$ in the DLH of length $b_{j}$ is given by

$$
C_{1 l}^{j}=F_{1 l}^{j} / F_{1 v}^{j}, \quad l=1,2, \quad j=1, \ldots, 4 .
$$

It is assumed that axial movement in the tubules is dominated by convection; thus diffusive flow is neglected in Equation (6). Physiological arguments in [7] and comparative computations in [8] justify this simplification.

Further details of the notation may be found in the glossary of symbols in Table 1. Note that Equations (2)-(6) are not self-contained, because they are coupled with other equations (which will be given below) via the CC concentrations $C_{6 l}$.

The ascending limbs of Henle's loop are impermeable to water [9, 10], and the ALH system is modeled by

$$
\begin{aligned}
& \frac{d F_{2 v}^{j}}{d s}=0, \quad j=1, \ldots, 4, \\
& \frac{d F_{2 l}^{j}}{d s}=-2 \pi r_{2} \cdot J_{2 l}^{j}, \quad l=1,2, \quad j=1, \ldots, 4 .
\end{aligned}
$$

The transmural fluxes are given by

$$
J_{2 l}^{j}=P_{2 l} \cdot\left(C_{2 l}^{j}-C_{6 l}\right)+T_{2 l}^{j}, \quad C_{2 l}^{j}=F_{2 l}^{j} / F_{2 v}^{j}
$$

The active transport $T_{2 l}^{j}$ is assumed to obey Michaelis-Menten kinetics, namely

$$
T_{2 l}^{j}=\frac{\mathrm{Vm}_{2 l} C_{2 l}^{j}}{\mathrm{Km}_{2 l}+C_{2 l}^{j}},
$$

where $\mathrm{Vm}_{2 l}$ is the maximum rate of transport, and $\mathrm{Km}_{2 l}$ is the Michaelis constant. In the model, only salt is transported actively (i.e. $T_{22}=0$ ), and this 
TABLE 1

GLOSSARY OF SYMBOLS ${ }^{\text {a }}$

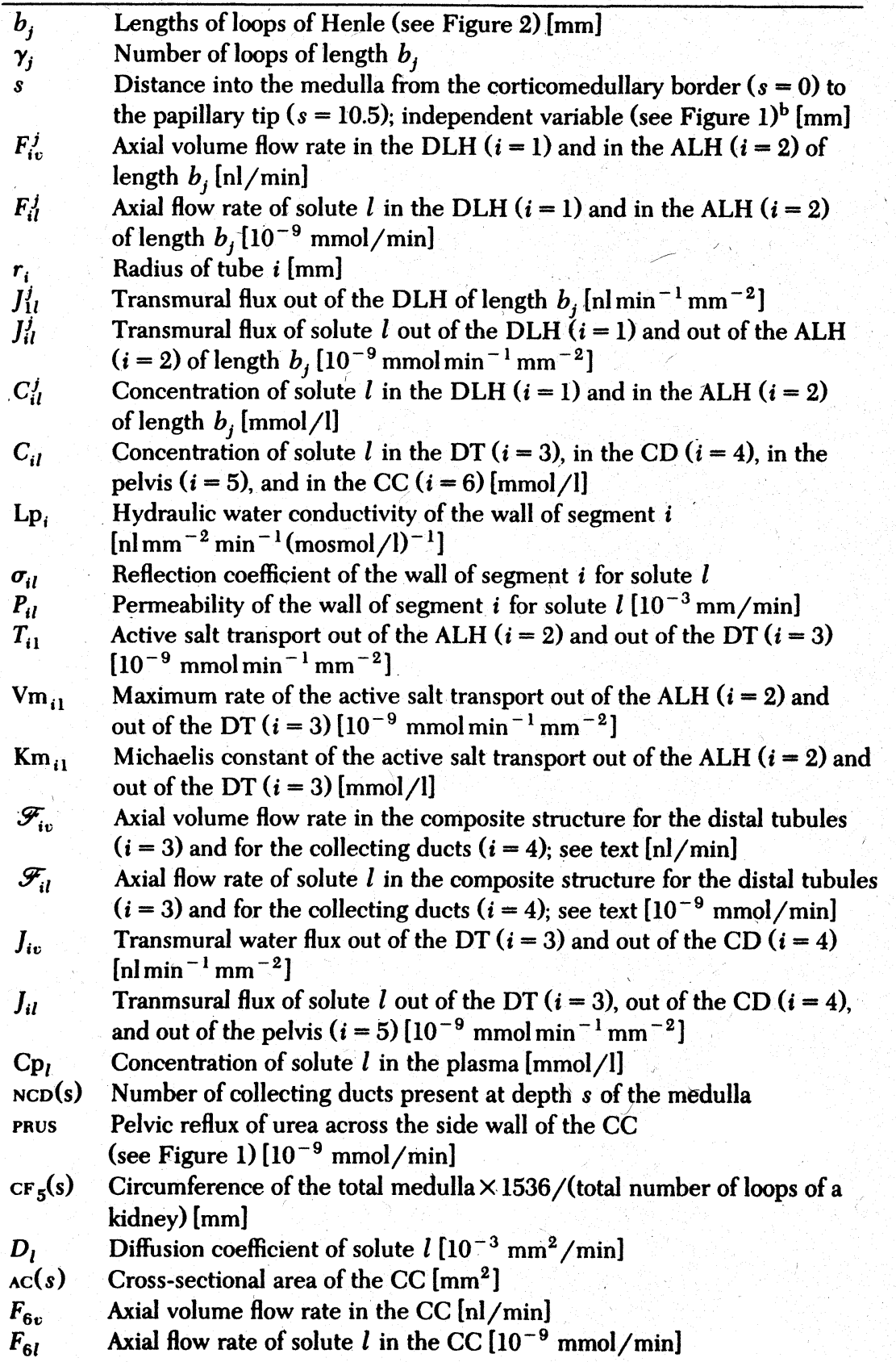

\section{TABLE 1 (Continued)}

$Q_{0} \quad$ Volume flow rate entering the $\mathrm{DLH}[\mathrm{nl} / \mathrm{min}]$

$L_{\mathrm{DT}} \quad$ Length of distal tubule [mm]

PRUC Pelvic reflux of urea across the cover wall of the CC (see Figure 1) $\left[10^{-9} \mathrm{mmol} / \mathrm{min}\right]$

In the order in which they appear in Equations (1)-(34)

${ }^{b}$ For $i=3, s$ is measured along the distal tubule. DLH (ALH), descending (ascending) limb of Henle's loop; DT, distal tubule; CD, collecting duct; CC, central core.

transport occurs only in the outer medullary section of the ALH and in the distal tubule (passive mode $[2,11]$ ).

The distal tubules are modeled by a composite structure (cf. [7]). The flows $\mathscr{F}_{3 v}, \mathscr{F}_{3 l}$ of the composite structure represent the sums of flows in the single tubules, and the concentrations

$$
C_{3 l}=\mathscr{F}_{3 l} / \mathscr{F}_{3 v}
$$

of the fluid within the composite structure reflect the mixture of the fluids in the single tubules. The 1536 distal tubules are modeled by

$$
\begin{aligned}
& \frac{d \mathscr{F}_{3 v}}{d s}=-2 \pi r_{3} \times 1536 J_{3 v}, \\
& \frac{d \mathscr{F}_{3 l}}{d s}=-2 \pi r_{3} \times 1536 J_{3 l}, \quad l=1,2 .
\end{aligned}
$$

Here, $s$ is measured along the distal tubules from $s=0$ to $s=L_{\mathrm{DT}}$. During this passage, the fluid interacts with the cortical interstitium, where the solute concentrations are assumed to be the same as in the arterial plasma, namely $\mathrm{Cp}_{1}$ and $\mathrm{Cp}_{2}$. Consequently,

$$
\begin{aligned}
J_{3 v} & =\mathrm{Lp}_{3}\left[1.82 \sigma_{31}\left(\mathrm{Cp}_{1}-C_{31}\right)+\sigma_{32}\left(\mathrm{Cp}_{2}-C_{32}\right)\right], \\
J_{3 l} & =P_{3 l} \cdot\left(C_{3 l}-\mathrm{Cp}_{l}\right)+\left(1-\sigma_{3 l}\right) J_{3 v} \bar{C}_{3 l}+T_{3 l}, \quad l=1,2,
\end{aligned}
$$

where $\bar{C}_{3 l}:=\left(C_{3 l}+C p_{l}\right) / 2$. Again, only salt is transported actively (i.e. $T_{32}=0$ ), and this active transport $T_{31}$ obeys. Michaelis-Menten kinetics. 
The geometry of the collecting duct system is described in [5]: Six nephrons drain into one collecting duct. Their number remains constant in the outer medulla. In the inner medulla, the collecting ducts merge in a dichotomous manner on eight successive levels. Consequently, the number of collecting ducts present at depth $s$ of the medulla is modeled by the function

$$
\operatorname{NCD}(s)= \begin{cases}256 & \text { for } 0 \leqslant s<4.5 \\ 128 \exp [-0.80867(s-4.5)] & \text { for } 4.5 \leqslant s \leqslant 10.5\end{cases}
$$

Note that $\operatorname{NCD}(10.5)=1$. Similarly to the distal tubules, the collecting-duct system is modeled by a composite structure:

$$
\begin{aligned}
& \frac{d \mathscr{F}_{4 v}}{d s}=-2 \pi r_{4} \cdot \mathrm{NCD}(s) \cdot J_{4 v}, \\
& \frac{d \mathscr{F}_{4 l}}{d s}=-2 \pi r_{4} \cdot \mathrm{NCD}(s) \cdot J_{4 l}, \quad l=1,2,
\end{aligned}
$$

where

$$
\begin{gathered}
J_{4 v}=\mathrm{Lp}_{4}\left[1.82 \sigma_{41}\left(C_{61}-C_{41}\right)+\sigma_{42}\left(C_{62}-C_{42}\right)\right], \\
J_{4 l}=P_{4 l} \cdot\left(C_{4 l}-C_{6 l}\right)+\left(1-\sigma_{4 l}\right) J_{4 v} \bar{C}_{4 l} \\
C_{4 l}=\frac{\mathscr{F}_{4 l}}{\mathscr{F}_{4 v}}, \quad \bar{C}_{4 l}=\frac{C_{4 l}+C_{6 l}}{2}
\end{gathered}
$$

The transmural flux of urea across the side wall of the CC is given by

$$
J_{52}=P_{52} \cdot\left(C_{52}-C_{62}\right),
$$

and the corresponding pelvic reflux amounts to

$$
\text { PRUS }=\int_{8.25}^{10.5} \mathrm{CF}_{5}(s) J_{52}(s) d s .
$$

This equation allows a trivial transformation to the differential equation

$$
\operatorname{prus}^{\prime}(s)=\mathrm{CF}_{5}(s) J_{52}(s):
$$

If $\operatorname{prus}(8.25)=0$, then PRUs $=\operatorname{prus}(10.5)$.

The differential equations (2)-(10), (16)-(22) are coupled by the CC concentrations $C_{6 l}$, which obey the central-core equations.

$$
F_{6 l}=F_{6 v} C_{6 l}-D_{l} \mathrm{AC}(s) \frac{d C_{6 l}}{d s}, \quad l=1,2,
$$

where $D_{l}$ is the diffusion coefficient of solute $l$, and $A C(s)$ denotes the cross-sectional area of the CC. Equation (23) allows solute movement along the $C C$ axis by both diffusion and convection. The central-core flows $F_{6 v}, F_{6 l}$ obey the following differential equations, which are derived from the requirement of mass balance:

$$
\begin{aligned}
\frac{d F_{6 v}}{d s}= & \sum_{j=j_{a}}^{4} \gamma_{j} 2 \pi r_{1} J_{1 v}^{j}+2 \pi r_{4} \operatorname{NCD}(s) J_{4 v}, \\
\frac{d F_{6 l}}{d s}= & \sum_{j=j_{a}}^{4} \gamma_{j}\left(2 \pi r_{1} J_{1 l}^{j}+2 \pi r_{2} J_{2 l}^{j}\right) \\
& +2 \pi r_{4} \mathrm{NCD}(s) J_{4 l}+\mathrm{CF}_{5}(s) J_{5 l}, \quad l=1,2,
\end{aligned}
$$

where $J_{51} \equiv 0$ for $s \in[0,10.5], J_{52} \equiv 0$ for $s \in[0,8.25]$, and $j_{a}=\nu$ for $s \in$ $\left[b_{v-1}, b_{v}\right](v=1, \ldots, 4)$.

The boundary conditions for the system of differential equations (2)-(25) are given by

$$
\begin{gathered}
F_{1 v}^{j}(0)=Q_{0}, \quad j=1, \ldots, 4, \\
F_{11}^{j}(0)=Q_{0} \mathrm{Cp}_{1}, \quad j=1, \ldots, 4, \\
F_{12}^{j}(0)=Q_{0} \times 2 \mathrm{Cp}_{2}, \quad j=1, \ldots, 4 ; \\
F_{2 v}^{j}\left(b_{j}\right)=-F_{1 v}^{j}\left(b_{j}\right), \quad j=1, \ldots, 4, \\
F_{2 l}^{j}\left(b_{j}\right)=-F_{1 l}^{j}\left(b_{j}\right), \quad j=1, \ldots, 4, \quad l=1,2 ; \\
\mathscr{F}_{3 v}(0)=-\sum_{j=1}^{4} \gamma_{j} F_{2 v}^{j}(0), \quad \mathscr{F}_{3 l}(0)=-\sum_{j=1}^{4} \gamma_{j} F_{2 l}^{j}(0), \quad l=1,2 ; \\
\mathscr{F}_{4 v}(0)=\mathscr{F}_{3 v}\left(L_{\mathrm{DT}}\right), \quad \mathscr{F}_{4 l}(0)=\mathscr{F}_{3 l}\left(L_{\mathrm{DT}}\right), \quad l=1,2 ; \\
\mathscr{P}_{42}(10.5)=\mathscr{F}_{4 v}(10.5) \cdot C_{52}+\mathrm{PRUS}+\mathrm{PRUC} ; \\
C_{6 l}(0)=\mathrm{Cp}_{l}, \quad l=1,2 ; \\
F_{6 v}(10.5)=F_{61}(10.5)=0, \quad F_{62}(10.5)=-\mathrm{PRUC},
\end{gathered}
$$

where pruc denotes the pelvic urea reflux across the cover wall of the CC. It 
is given by

$$
\text { PRUC }=\mathrm{AC}(10.5) \cdot P_{52}\left[C_{52}-C_{62}(10.5)\right]
$$

At the beginning of each tubule, the axial rate of flow of each constituent is fixed by the boundary conditions (26). The boundary conditions (27)-(29) serve to connect the ends of the descending limbs to the beginnings of the ascending limbs, the ends of the ascending limbs to the beginnings of the distal tubules, and the ends of the distal tubules to the beginnings of the collecting ducts. The boundary condition (31) results from the requirement of mass balance in the pelvis.

Equations (2)-(34) define a boundary-value problem for a system of 36 simultaneous nonlinear differential equations of first order with the unknown functions $F_{1 v}^{j}, F_{1 l}^{j}, F_{2 v}^{j}, F_{2 l}^{j}, \mathscr{F}_{3 v}, \mathscr{F}_{3 l}, \mathscr{F}_{4 v}, \mathscr{F}_{4 l}$, prus, $C_{6 l}, F_{6 v}, F_{6 l}(l=1,2 ; j$ $=1, \ldots, 4)$ and the unknown constant $C_{52}$ (eigenvalue problem). The geometric and thermodynamic parameters will be given in Section 4 .

Remark 2.1. In the simulations of Section 4, the four descending limbs have different lengths $b_{j}$, but apart from that, their parameters are identical. Consequently, the model (2)-(34) is equivalent to a model with a single descending limb. The index $j$ in Equations (2)-(6), (26), in the transmural DLH fluxes of (24), (25), and in the DLH flows of (27) can be dropped. Thus the number of differential equations can be reduced to 27 .

REMARK 2.2. The systems modeling technique used in this section has been employed previously by several authors to study various aspects of the integrated renal function $[1,4,7,8,12-20]$. Finite-difference methods [12-14, 16, 20-23], quasilinearization [1, 24-27], invariant imbedding [27-31], and multiple shooting $[4,17,32]$ have been suggested for the numerical solution of the resulting boundary-value problems. A semidiscrete method combining collocation and shooting has been given in [19, 33]. The classical theoretical results on the orders of convergence for pure collocation [34] extend to this semidiscrete modification.

\section{THE INVERSE PROBLEM AND ITS NUMERICAL SOLUTION}

The differential equations and boundary conditions of Section 2 constitute a multipoint boundary-value problem

$$
\begin{gathered}
z^{\prime}=\Phi(s, z ; p) \\
\beta\left(z\left(b_{0} ; p\right), \ldots, z\left(b_{4} ; p\right) ; p\right)=0
\end{gathered}
$$

where $p$ denotes a vector of parameters which are of thermodynamic and geometric nature. The values of these parameters can be determined only by difficult and time-consuming experimental techniques, and they are known only with considerable uncertainty. In the inverse approach of the present paper, they are allowed to vary within certain intervals, i.e.

$$
l \leqslant p \leqslant u,
$$

where $l$ and $u$ denote vectors of lower and upper bounds respectively. These intervals reflect the corresponding ranges of measurements. It has already been pointed out in Section 1 that a judgment of a given kidney model requires the knowledge of the optimal inner medullary concentration increase which can be generated by this model. So the objective function is given by

$$
\underset{p}{\operatorname{maximize}}\left[\mathrm{Osm}_{6}(10.5 ; p)-\mathrm{Osm}_{6}(4.5 ; p)\right]
$$

where

$$
\operatorname{Osm}_{i}(s ; p):=1.82 C_{i 1}(s ; p)+C_{i 2}(s ; p)
$$

denotes the total osmolarity in compartment $i$. In addition to (37), further constraints are imposed on the parameters: First, experimental results [35] demonstrate that the osmolarity of the collecting duct fluid at the papillary tip is nearly the same as that of the fluid in the adjacent central core at the same level. This fact is modeled by the constraint

$$
0.9 \operatorname{Osm}_{4}(10.5 ; p) \leqslant \operatorname{Osm}_{6}(10.5 ; p) \leqslant 1.1 \operatorname{Osm}_{4}(10.5 ; p)
$$

Second, the volume flow rate emerging from the final collecting duct into the pelvis exceeds a certain bound [36]:

$$
\mathrm{TF} / \mathrm{P} \text { inulin } \mathrm{CD}(10.5 ; p) \leqslant 400
$$

where

$$
\mathrm{TF} / \mathrm{P} \text { inulin } \operatorname{cD}(s ; p):=\frac{3 \times 1536 Q_{0}}{\mathscr{F}_{4 v}(s ; p)}
$$

denotes the simulated tubule-fluid-to-plasma ratio for the inulin concentra- 
tion in the collecting duct at level $s$. Third, the salt concentration at the outer-inner medullary junction of the central core is within certain bounds [37]:

$$
350 \leqslant C_{61}(4.5 ; p) \leqslant 500
$$

The numerical solution of the inverse problem (35) $-(43)$ follows the semidiscrete approach give in [33]: It makes use of the sparsity of the system (35) by exploiting the fact that the tubule equations are connected only via the central-core concentrations $C_{6 l}$. The method is based on splines as trial functions for these concentrations and on collocation of the central-core equations (23). Once these trial functions are given, the tubule equations and boundary conditions form a sequence of initial-value problems (each in the corresponding direction of flow). These initial-value problems are very stable.

The definition of the trial functions (splines) $C_{\Delta, 61}$ and $C_{\Delta, 62}$ requires the selection of a partition $\Delta=\left(s_{j}\right)_{j=0}^{N}$ of the interval $[0.0,10.5]$,

$$
\Delta: \quad 0.0=s_{0}<s_{1}<s_{2}<\cdots<s_{N}=10.5,
$$

which has to include the points $b_{1}, b_{2}, b_{3}$ where the right-hand side $\Phi$ of Equation (35) is discontinuous. For an adaptive placement of the partition points $s_{j}$, an adequately modified version of the code NEWNOT [38] is effective. The space of trial functions is given by

$$
\Pi_{k, \Delta} \cap C[0.0,10.5]
$$

where $\Pi_{k, \Delta}$ denotes the linear space of piecewise polynomials of degree $\leqslant k$ with partition points $\Delta$. A reasonable choice is $k=3$.

Normalized $B$-splines (cf. [38]) are used as basis functions. Let

$$
C_{\Delta, 6 l}=\sum_{j=1}^{k N+1} \alpha_{j l} B_{j, k+1}, \quad l=1,2
$$

be the $B$-representations for the trial functions. Because of the boundary conditions (32), $\alpha_{1 l}=\mathrm{Cp}_{l}$. So the $2 k N$-dimensional vector

$$
\alpha:=\left(\alpha_{21}, \ldots, \alpha_{k N+1,1}, \alpha_{22}, \ldots, \alpha_{k N+1,2}\right)
$$

has to be determined such that $C_{\Delta, 6 l}$ approximate $C_{6 l}(l=1,2)$. For that purpose collocation is applied to the central-core equations (23): Let $\sigma_{i}$ $(i=1, \ldots, k N)$ denote the Gauss-Legendre collocation points ( $k$ per subinterval of the partition $\Delta$, and distributed the same in each subinterval; see e.g. [38]). The trial functions are forced to exactly satisfy the differential equations (23) at these points, i.e.

$$
\mathrm{fc}_{i l}(\alpha, p)=0
$$

- where

$$
\begin{array}{r}
\mathrm{fc}_{i l}(\alpha, p):=C_{\Delta, 6 l}^{\prime}\left(\sigma_{i} ; \alpha\right)-\frac{F_{\Delta, 6 v}\left(\sigma_{i} ; \alpha, p\right) C_{\Delta, 6 l}\left(\sigma_{i} ; \alpha\right)-F_{\Delta, 6 l}\left(\sigma_{i} ; \alpha, p\right)}{D_{l} \cdot \mathrm{AC}\left(\sigma_{i} ; p\right)}=0, \\
i=1, \ldots, k N, \quad l=1,2 .
\end{array}
$$

Here, $F_{\Delta, 6 v}$ and $F_{\Delta, 6 l}$ together with $F_{\Delta, 1 v}, F_{\Delta, 1 l}, F_{\Delta, 2 v}^{j}, F_{\Delta, 2 l}^{j}, \mathscr{F}_{\Delta, 3 v}, \mathscr{F}_{\Delta, 3 l}$, $\mathscr{I}_{\Delta, 4 v}, \mathscr{F}_{\Delta, 4 l}^{2}$, prus $\Delta, C_{\Delta, 52}$ denote the solution of the differential equations (2)-(22), (24), (25) subject to the boundary conditions (26)-(31), (33), (34), where the concentrations $C_{6 l}$ in the right-hand sides of the differential equations and in (34) are replaced by the trial functions $C_{\Delta, 6 l}(l=1,2)$. Note that according to Remark 2.1 the index $j$ in the DLH flows can be dropped.

Owing to the typical connectivity of the system of the nephrons, the above functions can be computed efficiently in a natural and straightforward manner: The initial-value problems (2)-(6), (26) for the DLH; (7)-(10), (27) for the ALH; (11)-(15), (28) for the DT; (16)-(20), (29) for the CD are computed in sequence. For these integrations, routines are used that control the discretization error reliably, namely the programs DIFsyl (BulirschGragg-Stoer extrapolation method [39-41]), RKF7. (Runge-Kutta-Fehlberg method of order 7 [42]), and DGEAR (backward differentation formulas (43]). Note that these integrations always take place in the stable direction of tubular flow. At its end, the values of the functions $F_{\Delta, 1 v}, F_{\Delta, 1 l}, F_{\Delta, 2 v}^{j}, F_{\Delta, 2 l}^{j}$, $\mathscr{F}_{\Delta, 4 v}, \mathscr{F}_{\Delta, 4 l}$ at the collocation points and at the endpoints of the interval $[0.0,10.5]$ are available.

Equations (21), (22), (31), (34) can be combined to

$$
\mathscr{F}_{\Delta, 42}(10.5 ; \alpha, p)
$$

$$
=C_{\Delta, 52}(\alpha, p)
$$

$$
\begin{aligned}
& \times\left[\mathscr{F}_{\Delta, 4 v}(10.5 ; \alpha, p)+P_{52} \cdot\left(\int_{8.25}^{10.5} \mathrm{CF}_{5}(s ; p) d s+\mathrm{AC}(10.5 ; p)\right)\right] \\
& -P_{52} \cdot\left(\int_{8.25}^{10.5} \mathrm{CF}_{5}(s ; p) C_{\Delta, 62}(s ; \alpha) d s+\mathrm{AC}(10.5 ; p) C_{\Delta, 62}(10.5 ; \alpha)\right)
\end{aligned}
$$

and the constant $C_{\Delta, 52}(\alpha, p)$ can be easily computed from this equation. 
The computation of the functions $\mathrm{fc}_{i l}$ is completed by integrating the differential equations (3), (8), (17), (25) from $s=10.5$ to $s=\sigma_{i}$. This together with the boundary conditions (27), (33) yields (e.g. for $l=2$ )

$$
\begin{aligned}
F_{\Delta, 62}\left(\sigma_{i} ; \alpha, p\right)= & -\sum_{j=j_{a}}^{4} \gamma_{j}\left[F_{\Delta, 12}\left(\sigma_{i} ; \alpha, p\right)+F_{\Delta, 22}^{j}\left(\sigma_{i} ; \alpha, p\right)\right] \\
& -\mathscr{F}_{\Delta, 42}\left(\sigma_{i} ; \alpha, p\right)-\int_{\sigma_{i}}^{10.5} \mathrm{CF}_{5}(s ; p) J_{\Delta, 52}(s ; \alpha, p) d s \\
& +\mathscr{F}_{\Delta, 42}(10.5 ; \alpha, p)-\text { PRUC. }
\end{aligned}
$$

This equation describes the conservation of mass over the $\left[\sigma_{i}, 10.5\right]$ section of the medulla. It allows the straightforward calculation of $F_{\Delta, 62}\left(\sigma_{i} ; \alpha, p\right)$. The values $F_{\Delta, 6 v}\left(\sigma_{i} ; \alpha, p\right)$ and $F_{\Delta, 61}\left(\sigma_{i} ; \alpha, p\right)$ can be computed analogously. Hence, the functions $\mathrm{fc}_{i l}$ [ $\mathrm{cf}$. the definition (47)] can be evaluated in a stable and efficient manner.

Let $m$ be that index for which $s_{m}=4.5$ in the partition (44). Then the (discrete) nonlinear-programming problem which approximates the inverse problem (35)-(43) can be formulated:

$$
\operatorname{maximize} 1.82\left(\alpha_{k N+1,1}-\alpha_{k m+1,1}\right)+\left(\alpha_{k N+1,2}-\alpha_{k m+1,2}\right),
$$

where the independent variables $(\alpha, p)$ are subject to

nonlinear equality constraints:

$$
\mathrm{fc}_{i l}(\alpha, p)=0 \quad(i=1, \ldots, k N, \quad l=1,2) ;
$$

nonlinear inequality constraints:

$$
\begin{aligned}
& 0.9 \frac{1.82 \mathscr{F}_{\Delta, 41}(10.5 ; \alpha, p)+\mathscr{F}_{\Delta, 42}(10.5 ; \alpha, p)}{\mathscr{F}_{\Delta, 4 v}(10.5 ; \alpha, p)} \\
& \leqslant 1.82 \alpha_{k N+1,1}+\alpha_{k N+1,2} \\
& \leqslant 1.1 \frac{1.82 \mathscr{F}_{\Delta, 41}(10.5 ; \alpha, p)+\mathscr{F}_{\Delta, 42}(10.5 ; \alpha, p)}{\mathscr{F}_{\Delta, 4 v}(10.5 ; \alpha ; p)} \\
& 10 \leqslant \frac{3 \times 1536 Q_{0}}{\mathscr{F}_{\Delta, 4 v}(10.5 ; \alpha, p)} \leqslant 400
\end{aligned}
$$

bounds:

$$
\begin{gathered}
350 \leqslant \alpha_{k m+1,1} \leqslant 500, \\
l \leqslant p \leqslant u .
\end{gathered}
$$

Note that $\alpha_{k N+1, l}=C_{\Delta, 6 l}(10.5 ; \alpha, p)$ and $\alpha_{k m+1, l}=C_{\Delta, 6 l}(4.5 ; \alpha, p)$. Hence, the objective function (48) is an approximation of the original objective function (38). The equality constraints (49) are the collocation conditions (47). The inequalities (50) and the right inequality of (51) reflect the constraints (40) and (41) of the original problem. Note also that the flows $\mathscr{F}_{\Delta, 4 v}(10.5 ; \alpha, p)$ and $\mathscr{F}_{\Delta, 4 l}(10.5 ; \alpha, p)$ are computed as a by-product during the evaluation of the functions $\mathrm{fc}_{i l}(\alpha, p)$. The left inequality of (51) avoids calculations in a physiologically meaningless range. The bounds (52) and (53) correspond to (43) and (37) respectively.

For the numerical solution of the nonlinear programming problem (48)-(53) canned software is available. The package sLsQP [44] has been used for the computations in Section 4. It implements the sequential quadraticprogramming method algorithm as developed in [45-50]. This technique is also referred to as Lagrange-Newton or solver method [51]. Extensive tests in [52] on a wide range of test examples [53] have demonstrated its excellent efficiency in terms of function evaluations. This is a decisive feature because the evaluation of the constraint functions (49)-(51) is a rather time-consuming task.

In particular, SLSQP uses the exact L1 penalty function of [46] as a test function within the steplength algorithm. The matrices approximating the Hessian matrix of the Lagrangian function are updated by the BFGS formula of $[47,48]$. The quadratic-programming subproblems are transformed to linear least-squares problems [50], which are solved by the software of [54].

\section{SIMULATIONS AND RESULTS}

The techniques of Sections 2 and 3 have been applied during several simulations studying current research problems of renal physiology in [55]. The present section gives a small selection of these results.

Table 2 lists those thermodynamic parameters which are held fixed during the computations. They are discussed and justified in $[4,19]$. As far as possible values are those measured directly in isolated perfused tubules of the rabbit. In addition, $Q_{0}=10 \mathrm{nl} / \mathrm{min}, \mathrm{Cp}_{1}=140 \mathrm{mmol} / \mathrm{l}, \mathrm{Cp}_{2}=9 \mathrm{mmol} / \mathrm{l}$, $\mathrm{Km}_{21}=\mathrm{Km}_{31}=100 \mathrm{mmol} / \mathrm{l}$. The radii of the individual tubes are: $r_{1}=8$ $\mu \mathrm{m}, r_{2}=10 \mu \mathrm{m}, r_{4}=12 \mu \mathrm{m}$ in the outer medulla, $r_{4}=24 \mu \mathrm{m}$ in the inner 
TABLE 2

FIXED THERMODYNAMIC PARAMETERS *

\begin{tabular}{lcccccc}
\hline & \multicolumn{2}{c}{ ALH } & & \multicolumn{2}{c}{ CD } \\
\cline { 2 - 7 } & OM & IM & DT & OM & IM \\
\hline Lp, $\mathrm{nl} \mathrm{cm}^{-2} \mathrm{~min}^{-1}$ & 0 & 0 & 48.4 & Var. $^{\mathrm{b}}$ & Var. $^{\mathrm{b}}$ \\
$\times\left({\mathrm{mosmol} / \mathrm{l})^{-1}}^{-1}\right.$ & & & & & & \\
$P_{\text {salt }}, 10^{-5} \mathrm{~cm} / \mathrm{s}$ & 6.27 & 25 & 0.8 & 0 & 0 \\
$P_{\text {urea }}, 10^{-5} \mathrm{~cm} / \mathrm{s}$ & 0 & 6.7 & Lin. trans. & 0.097 & Var. $^{\mathrm{b}}$ \\
$\sigma_{\text {salt }}$ & - & - & 1 & 1 & 1 \\
$\sigma_{\text {urea }}$ & - & - & 1 & Var. $^{\mathrm{b}}$ & Var. $^{\mathrm{b}}$
\end{tabular}

aLH, ascending limb of Henle's loop; Dt, distal tubule; CD, collecting duct; OM, outer medulla; IM, inner medulla; Lp, hydraulic water conductivity; $P_{\text {salt }}$, permeability to salt; $P_{\text {urea }}$, permeability to urea; $\sigma_{\text {salt }}$, reflection coefficient for salt; $\sigma_{\text {urea }}$, reflection coefficient for urea.

${ }^{\mathrm{b}}$ Variable; see Table 3.

${ }^{\mathrm{c}}$ Linear transition from 0 to 1 .

medulla. The radius $r_{3}$ decreases linearly from 10 to $8 \mu \mathrm{m}$. The length of the distal tubule is $L_{\mathrm{DT}}=2.625 \mathrm{~mm}$. The cross-sectional area $\mathrm{AC}(s)$ of the central core and the circumference of the total medulla are chosen analogously to [4].

The other parameters are allowed to vary over certain intervals. These parameters constitute the vector $p$ of Section 3. The corresponding lower and upper bounds are given in Table 3. The chosen upper bounds for the maximum rates of active salt transport, $\mathrm{Vm}_{i 1}$, are relatively large in order to allow high flexibility. Note that in the results given below the computed optima for $\mathrm{Vm}_{i 1}$ are much lower than these upper bounds. The intervals for the DLH parameters cover the various modes that have been studied in [7]. The intervals for the $\mathrm{CD}$ parameters reflect the ranges of measurements. Cf. $[4,7,18,19]$ (together with the references cited there) and the recent results of [56]. Again, most of these measurements are in rabbits. The consequences of various permeabilities for the reentry of pelvic urea into the papillary central core have been studied in [4] (but see the discussion below). The lower bound for the parameter $\rho_{1}$ ensures that at least two-thirds of the loops are short loops [5]. However, no further restrictions are imposed on the loop geometry (within the frame inherent in the selection of four groups of loops with lengths $b_{1}, \ldots, b_{4}$ in Figure 2, of course). In the following, the above parameter set will be referred to as the base case. The bounds of Table 3 define the vectors $l$ and $u$ of the inequalities (37). The objective function (38) and the constraints (40)-(43) complete the definition of the inverse problem.
TABLE 3

BOUNDS FOR VARIABLE PARAMETERS

\begin{tabular}{|c|c|c|}
\hline Parameter & Lower bound & Upper bound \\
\hline \multicolumn{3}{|c|}{ Maximum rates of active transport } \\
\hline $\begin{array}{l}V_{21}, 10^{-6} \mathrm{mmol} \mathrm{cm}^{-2} \mathrm{~s}^{-1} \\
\mathrm{Vm}_{31}, 10^{-6} \mathrm{mmol} \mathrm{cm}^{-2} \mathrm{~s}^{-1}\end{array}$ & $\begin{array}{l}0 \\
0\end{array}$ & $\begin{array}{l}44 \\
44\end{array}$ \\
\hline \multicolumn{3}{|c|}{ Descending limb of Henle's loop } \\
\hline $\begin{array}{l}\mathrm{Lp}_{1}, \mathrm{nl} \mathrm{cm}^{-2} \min ^{-1}(\operatorname{mosmol} / \mathrm{l})^{-1} \\
P_{11}, 10^{-5} \mathrm{~cm} / \mathrm{s} \\
P_{12}, 10^{-5} \mathrm{~cm} / \mathrm{s} \\
\sigma_{11} \\
\sigma_{12}\end{array}$ & $\begin{array}{c}5 \\
0 \\
0 \\
0.36 \\
0.4\end{array}$ & $\begin{array}{c}252 \\
47 \\
20 \\
1 \\
1\end{array}$ \\
\hline \multicolumn{3}{|c|}{ Outer medullary collecting duct } \\
\hline $\begin{array}{l}\mathrm{Lp}_{4}, \mathrm{nl} \mathrm{cm}^{-2} \min ^{-1}(\mathrm{mosmol} / \mathrm{l})^{-1} \\
\sigma_{42}\end{array}$ & $\begin{array}{l}23 \\
0.4\end{array}$ & $\begin{array}{c}48.4 \\
1\end{array}$ \\
\hline \multicolumn{3}{|c|}{ Inner medullary collecting duct } \\
\hline $\begin{array}{l}\mathrm{Lp}_{4}, \mathrm{nl} \mathrm{cm}^{-2} \min ^{-1}(\operatorname{mosmol} / \mathrm{l})^{-1} \\
P_{42}, 10^{-5} \mathrm{~cm} / \mathrm{s} \\
\sigma_{42}\end{array}$ & $\begin{array}{l}7.37 \\
2.4 \\
0.4\end{array}$ & $\begin{array}{c}92 \\
13.1 \\
0.75\end{array}$ \\
\hline \multicolumn{3}{|c|}{ Pelvis } \\
\hline$P_{52}, 10^{-5} \mathrm{~cm} / \mathrm{s}$ & 1 & 15 \\
\hline \multicolumn{3}{|c|}{ Loop geometry } \\
\hline $\begin{array}{l}\rho_{1}:=\gamma_{1} / 1536 \\
\rho_{2}:=\gamma_{2} /\left[1536\left(1-\rho_{1}\right)\right] \\
\rho_{3}:=\gamma_{3} /\left[1536\left(1-\rho_{1}\right)\left(1-\rho_{2}\right)\right]\end{array}$ & $\begin{array}{l}\frac{2}{3} \\
0 \\
0\end{array}$ & $\begin{array}{l}1 \\
1 \\
1\end{array}$ \\
\hline
\end{tabular}

For the numerical solution of this inverse problem a partition with 14 subintervals and splines of degree $\leqslant 3$ are chosen (cf. Section 3 ). Thus, the discrete nonlinear-programming problem of Equations (48)-(53) consists of 100 independent variables, 84 nonlinear equality constraints, 4 nonlinear inequality constraints, and 34 bounds.

Tables 4,5 and Figures 3-5 give the results of these computations. The bounds of Table 3 are repeated in Table 4 for the convenience of the reader. The computed optima for $\rho_{1}, \rho_{2}, \rho_{3}$ corresponded to $\gamma_{1}=1024, \gamma_{2}=356$, $\gamma_{3}=0, \gamma_{4}=156$. Both the computed salt concentration in the central core (Figure 3 ) and the computed urea concentration in the central core (Figure 
TABLE 4

COMPUTED OPTIMA FOR THE VARIABLE PARAMETERS IN THE bASE CASE

\begin{tabular}{|c|c|c|c|}
\hline $\begin{array}{l}\text { Parameter } \\
\text { (for units see Table 3) }\end{array}$ & $\begin{array}{l}\text { Lower } \\
\text { bound }\end{array}$ & $\begin{array}{l}\text { Computed } \\
\text { optimum }\end{array}$ & $\begin{array}{l}\text { Upper } \\
\text { bound }\end{array}$ \\
\hline \multicolumn{4}{|c|}{ Maximum rates of active transport } \\
\hline $\begin{array}{l}\mathrm{Vm}_{21} \\
\mathrm{Vm}_{31}\end{array}$ & $\begin{array}{l}0 \\
0\end{array}$ & $\begin{array}{c}14.76 \\
8.82\end{array}$ & $\begin{array}{l}44 \\
44\end{array}$ \\
\hline \multicolumn{4}{|c|}{ Descending limb of Henle's loop } \\
\hline $\begin{array}{l}L p_{1} \\
P_{11} \\
P_{12} \\
\sigma_{11} \\
\sigma_{12}\end{array}$ & $\begin{array}{c}5 \\
0 \\
0 \\
0.36 \\
0.4\end{array}$ & $\begin{array}{c}\text { Upper bound } \\
\text { Lower bound } \\
\text { Lower bound } \\
0.93 \\
\text { Upper bound }\end{array}$ & $\begin{array}{l}252 \\
47 \\
20 \\
1 \\
1\end{array}$ \\
\hline \multicolumn{4}{|c|}{ Outer medullary collecting duct } \\
\hline $\begin{array}{l}\mathrm{Lp}_{4} \\
\sigma_{42}\end{array}$ & $\begin{array}{l}23 \\
0.4\end{array}$ & $\begin{array}{l}\text { Upper bound } \\
\text { Upper bound }\end{array}$ & $\begin{array}{c}48.4 \\
1\end{array}$ \\
\hline \multicolumn{4}{|c|}{ Inner medullary collecting duct } \\
\hline $\begin{array}{l}\mathrm{Lp}_{4} \\
P_{42} \\
\sigma_{42}\end{array}$ & $\begin{array}{l}7.37 \\
2.4 \\
0.4\end{array}$ & $\begin{array}{c}14.40 \\
\text { Lower bound } \\
\text { Lower bound }\end{array}$ & $\begin{array}{c}92 \\
13.1 \\
0.75\end{array}$ \\
\hline \multicolumn{4}{|c|}{ Pelvis } \\
\hline$P_{52}$ & 1 & Upper bound & 15 \\
\hline \multicolumn{4}{|c|}{ Loop geometry } \\
\hline$\rho_{1}$ & $\frac{2}{3}$ & Lower bound & 1 \\
\hline$\rho_{2}$ & 0 & 0.695 & 1 \\
\hline$\rho_{3}$ & 0 & Lower bound & 1 \\
\hline
\end{tabular}

4) are in satisfactory agreement with slice concentration measurements. The increase of the osmolarity in the inner medullary central core is moderately strong (Figure 5). Note that this is the objective function (38). Thus, the present model cannot explain stronger increases of inner medullary concentrations.

Some comments on the computed optima of the variable parameters in Table 4 seem in place: The second group of parameters in this table is related to the descending limbs of Henle's loops (DLH). The computed optima for these parameters demonstrate that the water recycling mode of DLH equilibration is most effective. This confirms the direct parameter
TABLE 5

COMPUTED TUBULE FLUID-TO-PLASMA RATIO FOR THE INULIN CONCENTRATION (BASE CASE)

\begin{tabular}{cccccccccc}
\hline & \multicolumn{10}{c}{ Ratio } \\
\cline { 2 - 9 }$s$ & DLH1 & ALH1 & DLH2 & ALH2 & DLH3 & ALH3 & DLH4 & ALH4 & CD \\
\hline 0 & 3 & 8.77 & 3 & 9.55 & - & - & 3 & 20.83 & 36.22 \\
1.5 & 3.90 & 8.77 & 3.90 & 9.55 & - & - & 3.90 & 20.83 & 51.09 \\
4.5 & 8.77 & 8.77 & 8.77 & 9.55 & - & - & 8.77 & 20.83 & 114.50 \\
6.0 & & & 9.55 & 9.55 & - & - & 9.55 & 20.83 & 158.19 \\
8.25 & & & & & - & - & 13.67 & 20.83 & 277.53 \\
10.5 & & & & & & & 20.83 & 20.83 & 400 \\
\hline
\end{tabular}

${ }^{\mathrm{a}} \mathrm{DLH} j(\mathrm{ALH} j)$, descending (ascending) limb of Henle's loop of length $b_{j}$; $\mathrm{CD}$, collecting duct.

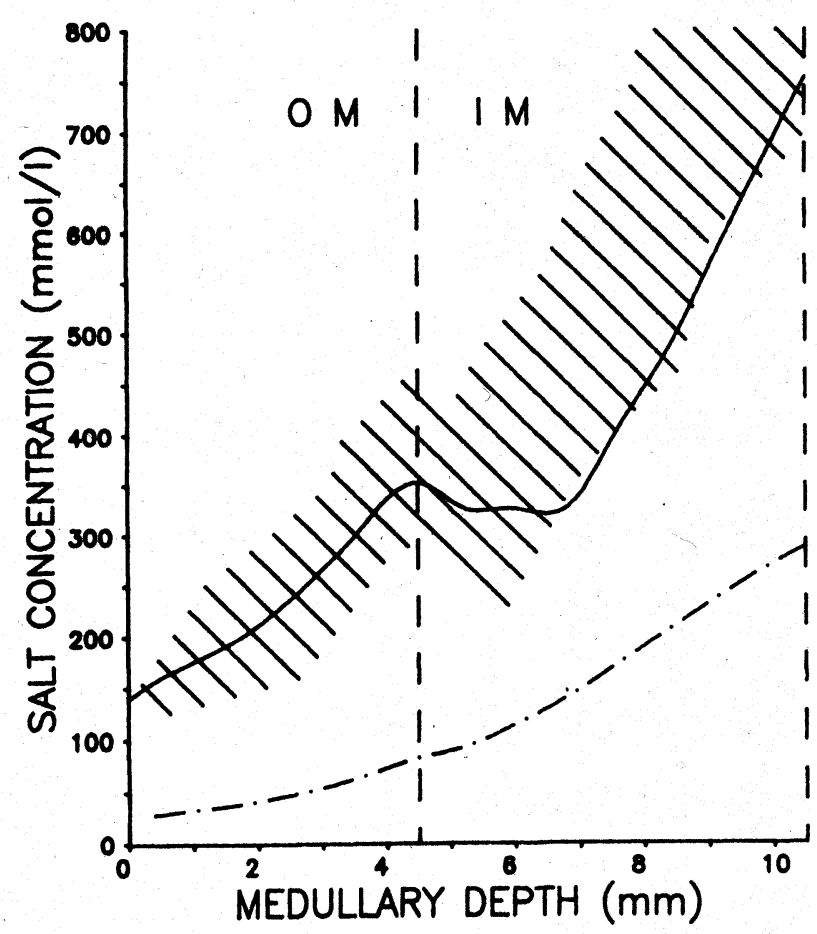

Fic 3. Computed salt concentration for the base case in the central core (-) and in the collecting duct $(-\cdot-\cdot)$; for comparison also measured slice concentrations [37] are given (hatched area); OM (IM), outer (inner) medulla. 


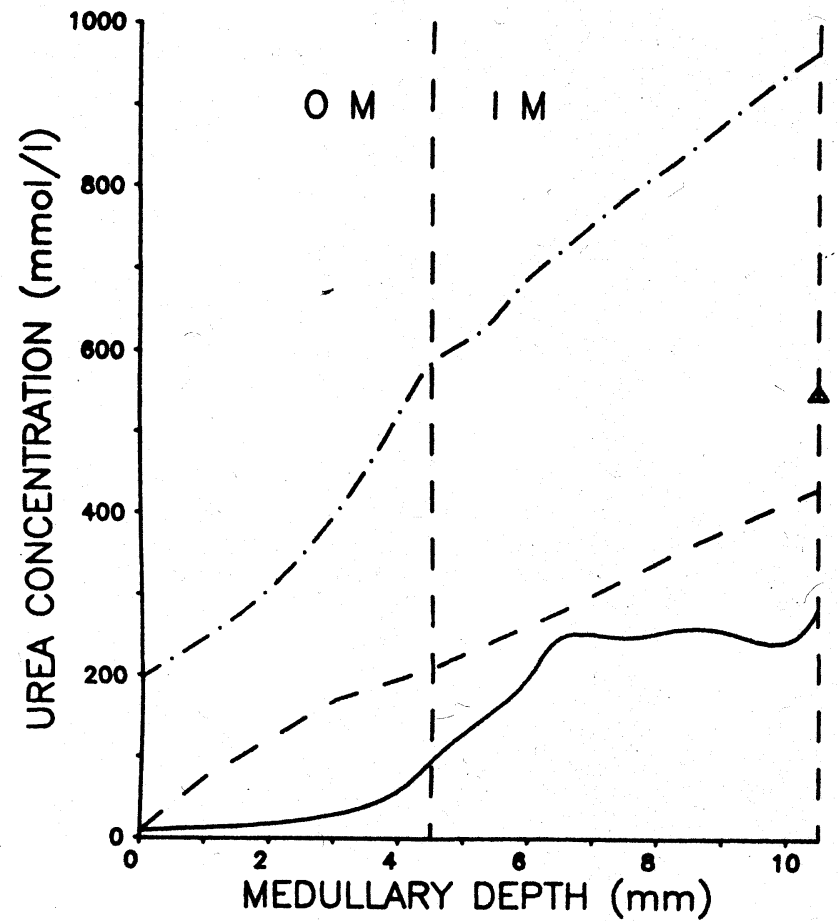

Fic. 4. Computed urea concentration for the base case in the central core (-), in the collecting duct $(-\cdot-\cdot)$, and in the pelvis $(\Delta)$; for comparison also measured slice concentrations [57] are given (- - -); OM (IM), outer (inner) medulla.

study in [7]. The computed optima for the last group of parameters in Table 4 show that a decreasing loop-of-Henle population as a function of increasing medullary depth is an important factor in the concentrating mechanism. The concentration capability of the present model is well above that of an otherwise similar model with only a single type of nephrons (see [55]). This is consistent with the direct parameter studies in $[16,58,59]$.

The computed optimum for the urea permeability of the wall separating the pelvis and the papillary central core $\left(P_{52}\right)$ allows a rather large amount of pelvic urea reflux. This together with the low urea permeability of the inner medullary collecting duct has a "delay effect" (cf. [4]): The entry of a high percentage of the inner medullary collecting duct urea load into the central core is delayed to the innermost depths of the medulla. This supports urea trapping in the inner medullary central core, which is a decisive feature for the passive concentration mechanism $[2,11]$.

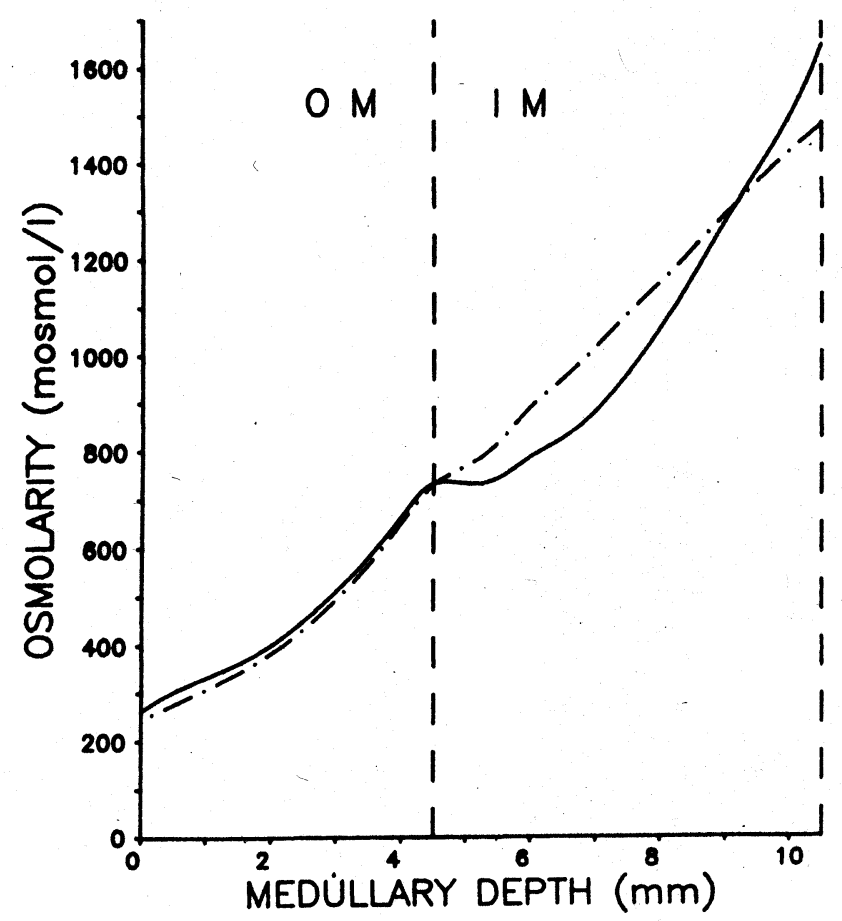

Fig. 5. Computed osmolarity for the base case in the central core (-) and in the collecting duct (-•-•); OM (IM), outer (inner) medulla.

However, in a recent study [56] such urea reentry from the pelvis has been judged to be insignificant under normal steady-state conditions. Moreover, the corresponding permeability in the rabbit was measured to be an order of magnitude smaller than the computed optimum for $P_{52}$ in Table 4. For a nonrabbit species, similar results have been reported in [60].

A delay effect (see above) is not necessarily restricted to the presence of pelvic urea reflux. Recent experiments [56], which have been inspired by mathematical modeling studies in [18], demonstrate a remarkable heterogeneity with respect to urea permeability of the inner medullary collecting duct. The urea permeability in the innermost part of the inner medullary collecting is found to be significantly higher than that in the outer third of this tubular segment. Obviously, this pattern allows a delay effect, too.

In order to study the functional implications of this heterogeneity by the inverse approach, the inner medullary collecting duct is subdivided into three parts. In the outermost part $(4.5 \leqslant s \leqslant 6.5)$, the urea permeability $\left(P_{42}\right.$, 
$\left.10^{-5} \mathrm{~cm} / \mathrm{s}\right)$ is allowed to vary between the bounds 1.1 [56] and 2.4 [61]. In the innermost part $(8.25 \leqslant s \leqslant 10.5)$, the corresponding bounds are 2.4 [61] and 14.9 [56]. The interval $6.5 \leqslant s \leqslant 8.25$ is modeled as a linear transition zone for $P_{42}$. The upper bound for $P_{52}$ is an order of magnitude smaller than that in the base case [56]. The other bounds for the variable parameters are the same as in the base case (Table 3). The fixed parameters (Table 2), the inequality constraints (40)-(43), and the objective function (38) are identical

\section{TABLE 6}

COMPUTED OPTIMA FOR THE VARIABLE PARAMETERS IN THE HETEROGENEOUS COLLECTING-DUCT CASE

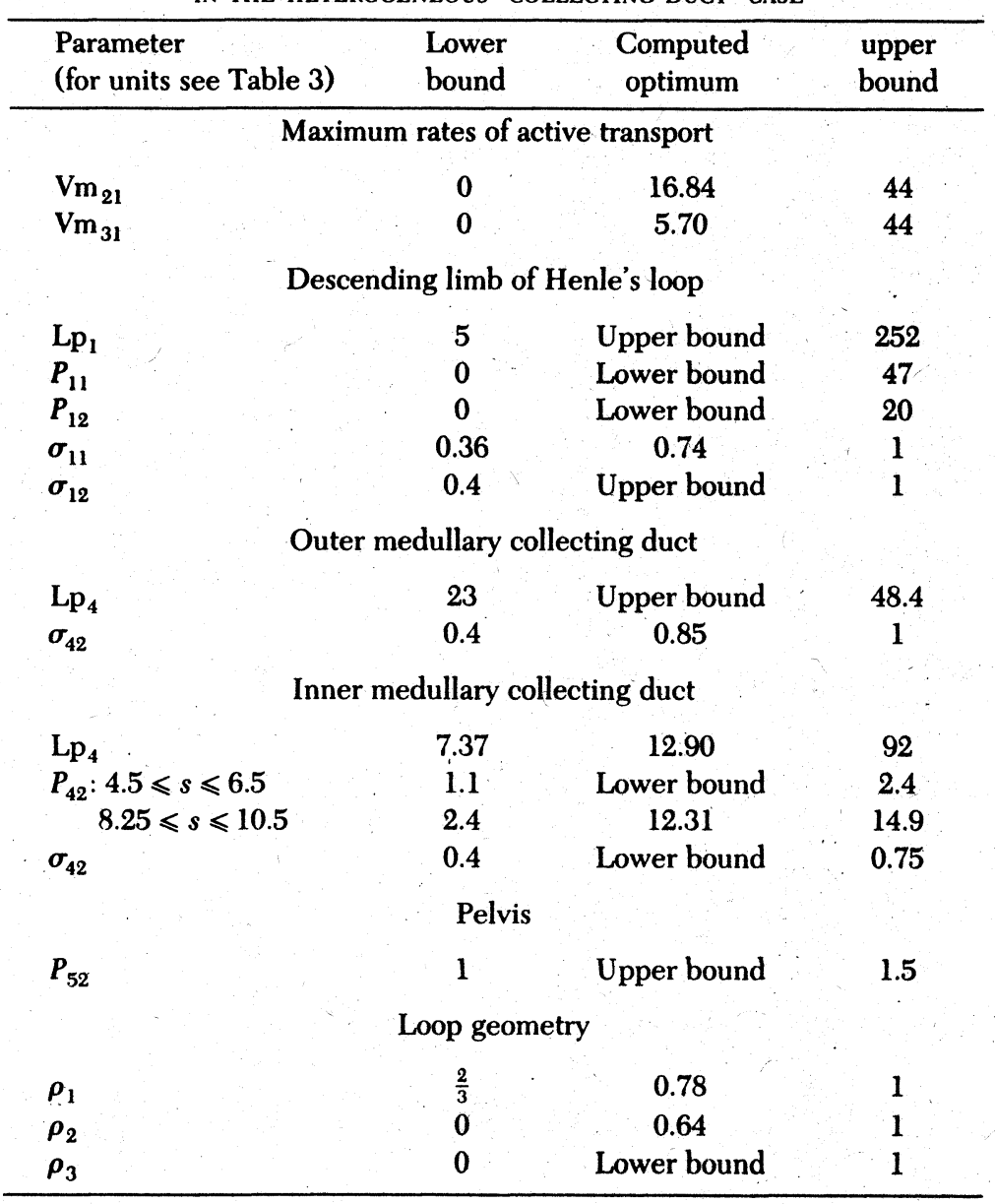

TABLE 7

COMPUTED TUBULE FLUID-TO-PLASMA RATIO FOR THE INULIN CONCENTRATION (HETEROGENEOUS COLLECTING-DUCT CASE)

\begin{tabular}{|c|c|c|c|c|c|c|c|c|c|}
\hline \multirow[b]{2}{*}{$s$} & \multicolumn{9}{|c|}{ Ratio } \\
\hline & DLH1 & ALH1 & DLH2 & ALH2 & DLH3 & ALH3 & DLH4 & ALH4 & CD \\
\hline 0 & 3 & 11.37 & 3 & 14.05 & - & - & 3 & 22.48 & 38.64 \\
\hline 1.5 & 3.76 & 11.37 & 3.76 & 14.05 & - & - & 3.76 & 22.48 & 59.14 \\
\hline 4.5 & $11: 37$ & 11.37 & 11.37 & 14.05 & - & - & 11.37 & 22.48 & 142.32 \\
\hline 6.0 & & & 14.05 & 14.05 & - & - & 14.05 & 22.48 & 208.78 \\
\hline 8.25 & & & & & - & - & 20.20 & 22.48 & 320.14 \\
\hline 10.5 & & & & & & & 22.48 & 22.48 & 400 \\
\hline
\end{tabular}

" DLH $j$ (ALH $j$ ), descending (ascending) limb of Henle's loop of length $b_{j}$; $\mathrm{CD}$, collecting duct.

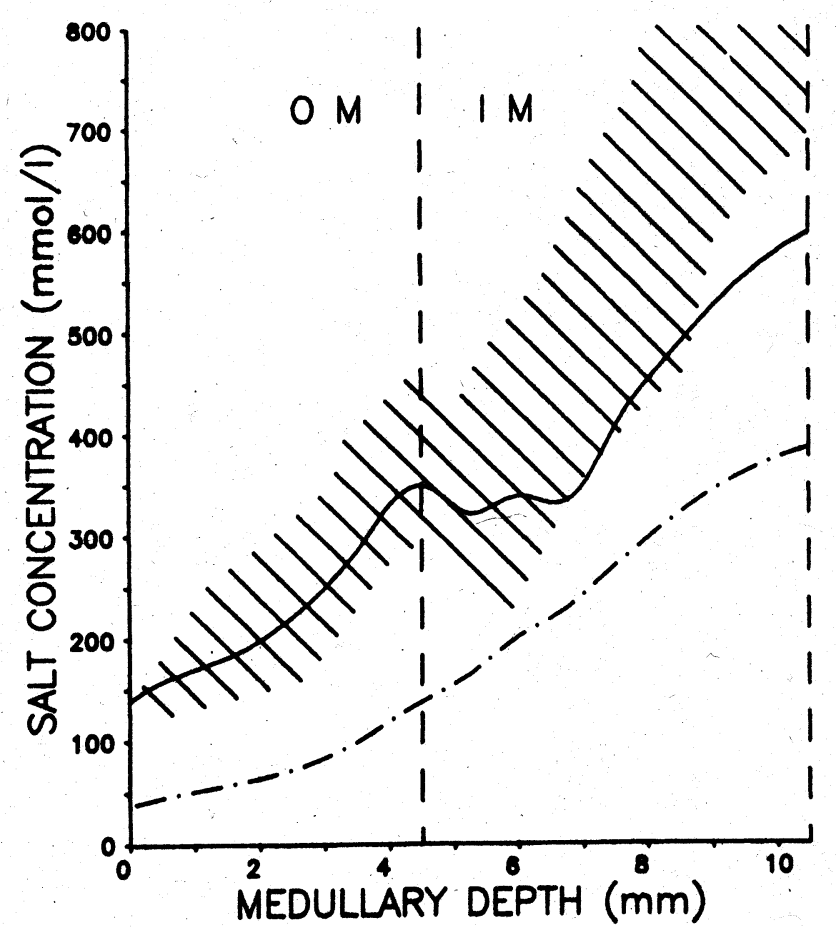

FiG. 6. Computed salt concentration for the heterogeneous collecting-duct case in the central core (-) and in the collecting duct $(-\cdot-)$; for comparison also measured slice concentrations [37] are given (hatched area); OM (IM) outer (inner) medulla. 


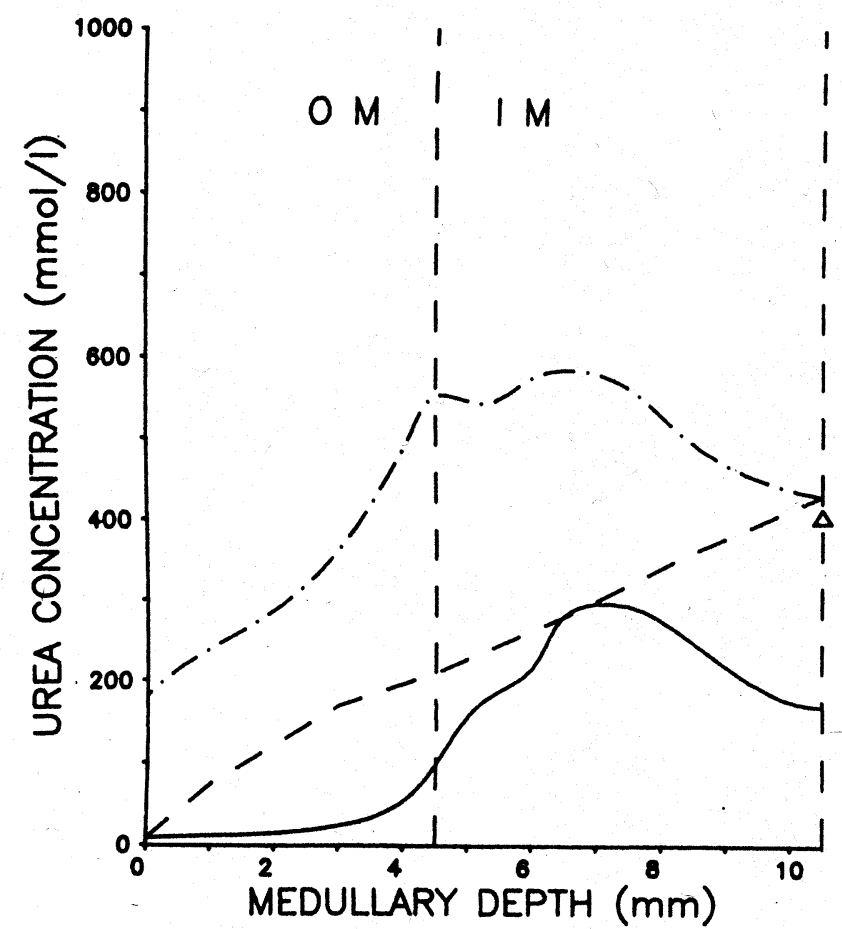

Fig. 7. Computed urea concentration for the heterogeneous collecting-duct case in the central core $(-)$, in the collecting duct $(-\cdot-\cdot)$, and in the pelvis $(\Delta)$; for comparison also measured slice concentrations [57] are given (- - -); OM (IM), outer (inner) medulla.

to those of the base case as well. In the following, this inverse problem will be referred to as the heterogeneous collecting-duct case.

Tables 6,7 and Figures 6-8 give the results of these computations. The computed optima for $\rho_{1}, \rho_{2}, \rho_{3}$ correspond to $\gamma_{1}=1195, \gamma_{2}=217, \gamma_{3}=0$, $\gamma_{4}=124$. The computed optima for $P_{42}$ are in accord with the delay effect suggested in [56]. Because of the optimal selection of the variable parameters by the inverse approach, the computed increase of the osmolarity in the inner medullary central core (cf. Figure 8) is considerably stronger than the corresponding increase in the simulations of [18]. Note that the latter simulations also model inner medullary collecting duct heterogeneity. Nethertheless, a comparison of Figures 6-8 with Figures 3-5 reveals that the delay effect produced by the collecting duct heterogeneity is less efficient than the corresponding delay effect in the base case, which is due to pelvic urea reflux.

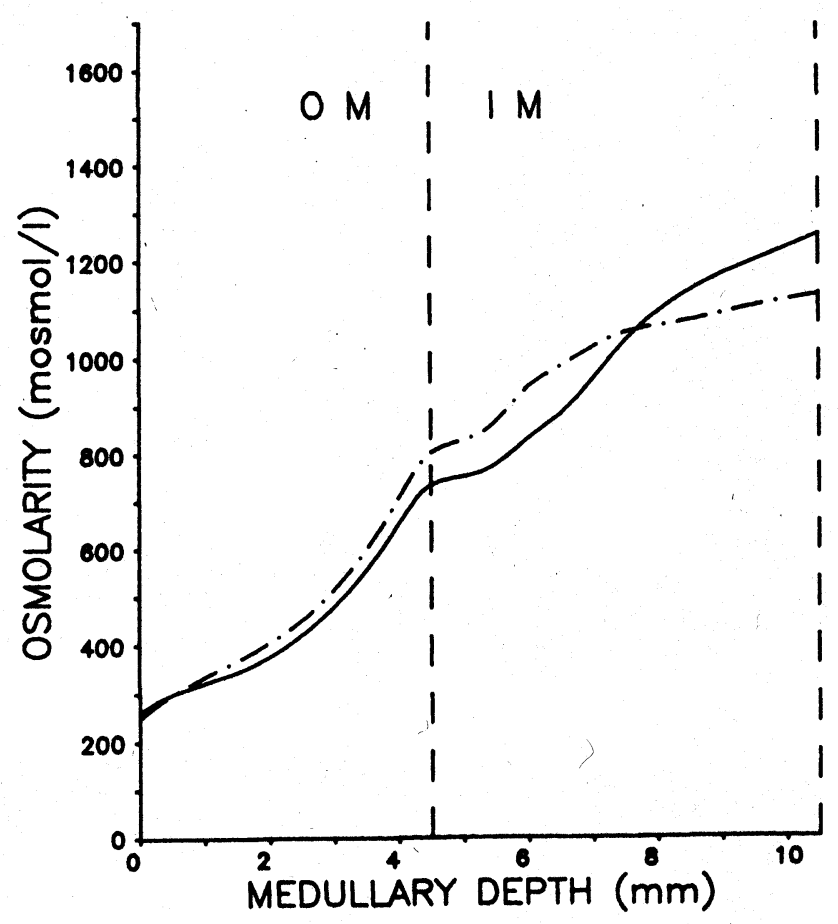

Fic. 8. Computed osmolarity for the heterogeneous collecting-duct case in the central core (-) and in the collecting duct (-·-); OM (IM), outer (inner) medulla.

\section{DISCUSSION}

The inverse approach presented in Sections 2-4 allows rigorous judgement of the potential of a given kidney modeling technique by determining the optimal inner medullary concentration increase. Note that the central core is an idealization that does not take into account the possible dissipative losses due to the system of the vasa recta (see [1]). Thus, the computed optimal inner medullary concentration increases of the present paper are upper bounds for those increases that would be predicted by a model that includes the vasa recta as separate structures. In spite of this idealization, the results of the base case are consistent only with the flattest measured inner medullary concentration profiles (cf. Figures 3,4 ). If the pelvic urea reflux is restricted according to recent measurements (heterogeneous collecting-duct case), the agreement is not satisfactory (cf. Figures 6, 7). However, the situation improves drastically, if a "salt transport cascade" $[19,62]$ is included 
in the model. Such a transport cascade occurs if the upper parts of the long descending limbs of Henle's loops are able to secrete salt actively into the tubular fluid. This feature has been included in a model which is otherwise similar to that given here [19]. For this model, the inverse approach was able to determine a parameter set which predicts a very strong concentration increase over the inner medullary central core (osmolarity at the inner outer medullary junction $s=4.5: 976 \mathrm{mosmol} / \mathrm{l}$; at the papillary tip, $s=10.5: 4343$ mosmol/l; see [55]).

At present, the assumption of active salt transport into certain parts of the descending limbs of Henle's loops is backed only by morphological observations and lacks experimental evidence. However, it has been pointed out recently [63] that a salt transport cascade is not necessarily restricted to the presence of active salt transport into the descending limbs and could operate on the basis of the complementary processes of cycles and separations as well. A verification of this suggestion requires further modeling efforts.

\section{REFERENCES}

1 A. S. Wexler, R. E. Kalaba, and D. J. Marsh, Passive, one-dimensional countercurrent models do not simulate hypertonic urine formation, Amer. J. Physiol. 253 (Renal Fluid Electrolyte Physiol. 22):F1020-F1030 (1987)

2 J. L. Stephenson, Concentration of urine in a central core model of the renal counterflow system, Kidney Internat. 2:85-94 (1972).

3 R. B. Kellogg, Some Singular Perturbation Problems in Renal Models, Manuscript, Univ. of Maryland, College Park, Md., 1988.

4 P. Lory, A. Gilg, and M. Horster, Renal countercurent system: Role of collecting duct convergence and pelvic urea predicted from a mathematical model, $J$. Math. Biol. 16:281-304 (1983).

5 W. Kriz, Structural organization of the renal medulla: Comparative and functional aspects, Amer. J. Physiol. 241 (Regulatory Integrative Comp. Physiol. 10):R3-R26 (1981).

6 A. Katchalsky and P. F. Curran, Nonequilibrium Thermodynamics in Biophysics, Harvard U.P., Cambridge, Mass., 1967.

7 L. C. Moore and D. J. Marsh, How descending limb of Henle's loop permeability affects hypertonic urine formation, Amer. J. Physiol. 239 (Renal Fluid Electrolyte Physiol. 8):F57-F71 (1980).

8 A. Gilg, Simulationen an einem zeitabhängigen Modell des Gegenstromsystems der Niere, in Simulationstechnik, Informatik-Fachber. 109 (D. F. P. Möller, Ed.), Springer-Verlag, Berlin, 1985.

9 A. Rocha and J. P. Kokko, Sodium chloride and water transport in the medullary thick ascending limb of Henle, J. Clinical Investigation 52:612-623 (1973).

10 M. Imai and J. P. Kokko, Sodium chloride, urea and water transport in the thin ascending limb of Henle: Generation of osmotic gradients by passive diffusion of solutes, J. Clinical Investigation 53:393-402 (1974).
11 J. P. Kokko and F. C. Rector, Countercurrent multiplication system without active transport in inner medulla, Kidney Internat. 2:214-223 (1972).

12 J. L. Stephenson, R. P. Tewarson, and R. Mejia, Quantitative analysis of mass and energy balance in non-ideal models of the renal counterflow system, Proc. Nat. Acad. Sci. U.S.A. 71:1618-1622 (1974).

13 J. L. Stephenson, R. Mejia, and R. P. Tewarson, Model of solute and water movement in the kidney, Proc. Nat. Acad. Sci. U.S.A. 73:252-256 (1976).

14 R. Mejia and J. L. Stephenson, Numerical solution of multinephron kidney equations, J. Comput. Phys. 32:325-246 (1979).

15 L. C. Moore, D. J. Marsh, and C. M. Martin, Loop of Henle during the water-to-antidiuresis transition in Brattleboro rats, Amer. J. Physiol. 239 (Renal Fluid Electrolyte Physiol. 8):F72-F83 (1980).

16 R. Mejia and J. L. Stephenson, Solution of multinephron, multisolute model of the mammalian kidney by Newton and continuation methods, Math. Biosci. 68:279-298 (1984).

17 M. Horster, A. Gilg, and P. Lory, Determinants of axial osmotic gradients in the differentiating countercurrent system, Amer. J. Physiol. 246 (Renal Fluid Electrolyte Physiol. 15):F124-F132 (1984).

18 P. S. Chandhoke, G. M. Saidel, and M. A. Knepper, Role of inner medullary collecting duct $\mathrm{NaCl}$ transport in urinary concentration, Amer. J. Physiol. 249 (Renal Fluid Electrolyte Physiol. 18):F688-F697 (1985).

19 P. Lory, Effectiveness of a salt transport cascade in the renal medulla: Computer simulations, Amer. J. Physiol. 252 (Renal Fluid Electrolyte Physiol. 21):F1095-F1102 (1987).

20 J. L. Stephenson, Y. Zhang, A Eftekhari, and R. Tewarson, Electrolyte transport in a central core model of the renal medulla, Amer. J. Physiol. 253 (Renal Fluid Electrolyte Physiol. 22):F982-F997 (1987).

21 R. Mejia, R. B. Kellogg, and J. L. Stephenson, Comparison of numerical methods for renal network flows, J. Comput. Phys. 23:53-62 (1977).

22 R. P. Tewarson and S. Gupta, A sparse matrix method for renal models, Math. Biosci. 61:191-203 (1982).

23 R. P. Tewarson, J. L. Stephenson, M. Garcia, and Y. Zhang, On the solution of equations for renal counterflow models, Comput. Biol. and Med. 15:287-295 (1985).

24 R. E. Bellman and R. E. Kalaba, Quasilinearization and Nonlinear Boundary Value Problems, Elsevier, New York, 1965.

25 A. S. Wexler, R. E. Kalaba, and D. J. Marsh, Automatic derivative evaluation in solving boundary value problems: The renal medulla, Amer. J. Physiol. 251 (Renal Fluid Electrolyte Physiol. 20):F358-F378 (1986).

26 A. Wexler, Solution of nonlinear boundary value problems coupled to a system of algebraic equations using quasilinearization, Nonlinear Anal. 11:691-696 (1987).

27 R. E. Kalaba and A. S. Wexler, New methods for boundary value problems, Math. Comput. Modelling 11:855-857 (1988).

28 M. R. Scott, Invariant Imbedding and its Applications to Ordinary Differential Equations, Addison-Wesley, Reading Mass., 1973. 
29 J. Casti and R. Kalaba, Imbedding Methods in Applied Mathematics, AddisonWesley, Reading, Mass., 1973.

30 J. Buell, R. Kalaba, and D. Marsh, On a boundary value problem in the theory of urine formation, Appl. Math. Comput. 5:55-67 (1979).

31 A. S. Wexler, R. E. Kalaba, L. S. Tesfatsion, and D. J. Marsh, An invariantimbedding solution of general linear two-point boundary-value problems, Appl. Math. Comput. 26:237-244 (1988).

32 J. Stoer and R. Bulirsch, Introduction to Numerical Analysis, Springer-Verlag, New York, 1980.

33 P. Lory, Ein Semi-Kollokationsverfahren zur numerischen Lösung von Nierenmodellen, Report TUM-M8501, Technische Univ. München, Mathematisches Institut, München, West Germany, 1985.

34 C. de Boor and B. Swartz, Collocation at Gaussian points, SIAM J. Numer. Anal. 10:582-606 (1973).

35 C. W. Gottschalk and M. Mylle, Micropuncture study of the mammalian urinary concentrating mechanism: Evidence for the countercurrent hypothesis, Amer. J. Physiol. 196:927-936 (1959).

36 R. E. Oliver, D. R. Roy, and R. L. Jamison, Urinary concentration in the papillary collecting duct of the rat, J. Clinical Investigation 69:157-164 (1982).

37 H. Koepsell, W. A. P. Nicholson, W. Kriz, and H. J. Höhling, Measurements of exponential gradients of sodium and chlorine in the rat kidney medulla using the electron microprobe, Pfluegers Arch. 350:167-184 (1974).

38 C. de Boor, A Practical Guide to Splines, Springer-Verlag, New York, 1978.

39 R. Bulirsch and J. Stoer, Numerical treatment of ordinary differential equations by extrapolation methods, Numer. Math. 8:1-13 (1966).

40 W. B. Gragg, On extrapolation algorithms for ordinary initial value problems, SIAM J. Numer. Anal. 2:384-403 (1965).

41 H. G. Hussels, Schrittweitensteuerung bei der Integration gewöhnlicher Differentialgleichungen mit Extrapolationsverfahren, Diplomarbeit, Univ. Köln, mathematisches Inst., Köln, West Germany, 1973.

42 E. Fehlberg, Klassische Runge-Kutta Formeln fünfter und siebenter Ordnung mit Schrittweitenkontrolle, Computing 4:93-106 (1969).

43 C. W. Gear, Numerical Initial Value Problems in Ordinary Differential Equations, Prentice-Hall, Englewood Cliffs, N.J., 1971.

44 D. Kraft, A Software Package for Sequential Quadratic Programming, Report DFVLR-FB 88-28, Deutsche Foschungs- und Versuchsanstalt für Luft- und Raumfahrt, Oberpfaffenhofen, West Germany, 1988.

45 R. B. Wilson, A simplicial algorithm for concave programming, Ph.D. Thesis, Graduate School of Business Administration, Harvard Univ., Cambridge, Mass., 1963.

46 S.-P. Han, A globally convergent method for nonlinear programming, J. Optim. Theory Appl. 22:297-309 (1977).

47 M. J. D. Powell, A fast algorithm for nonlinearily constrained optimization calculations, in Numerical Analysis, Proceedings of the Biennial Conference Held at Dundee, June 1977, Lecture Notes in Math. 630 (G. A. Watson, Ed.), Springer-Verlag, Berlin, 1978.
48 M. J. D. Powell, The convergence of variable metric methods for nonlinearly constrained optimization calculations, in Nonlinear Programming, No. 3 (O. L Mangasarian, R. R. Meyer, and S. M. Robinson, Eds.), Academic, New York, 1978.

49 K. Schittkowski, The nonlinear programming method of Wilson, Han, and Powell with an augmented Lagrangian type line search function, Part 1: Convergence analysis, Numer. Math. 38:83-114 (1981).

50 K. Schittkowski, The nonlinear programming method of Wilson, Han, and Powell with an augmented Lagrangian type line search function, Part 2: An efficient implementation with linear least squares subproblems, Numer. Math. 38:115-127 (1981).

51 R. Fletcher, Practical Methods of Optimization, Vol. 2, Constrained Optimization, Wiley, Chichester, 1981.

52 K. Schittkowski, Nonlinear Programming Codes. Information, Test, Performance, Lecture Notes in Econom. and Math. Systems 183, Springer-Verlag, Berlin, 1980.

53 W. Hock and K. Schittkowski, Test Examples for Nonlinear Programming Codes, Lecture Notes in Econom. and Math. Systems 187, Springer-Verlag, Berlin, 1981.

54 C. L. Lawson and R. J. Hanson, Solving Least Squares Problems, Prentice-Hall, Englewood Cliffs, N.J., 1974.

55 M. Breinbauer, Das Nierenmodell als inverses Problem, Diplomarbeit, Technische Univ. München, Mathematisches Inst., München, West Germany, 1988.

56 J. M. Sands and M. A. Knepper, Urea permeability of mammalian inner medullary collecting duct system and papillary surface epithelium, J. Clinical Investigation 79:138-147 (1987).

57 R. A. Gunther and L. Rabinowitz, Urea and renal concentrating ability in the rabbit, Kidney Internat. 17:205-222 (1980).

58 H. E. Layton, Distribution of Henle's loops may enhance urine concentrating capability, Biophysical J. 49:1033-1040 (1986).

59 H. E. Layton, Urea transport in a distributed loop model of the urine concentrating mechanism, Amer. J. Physiol. 258 (Renal Fluid Electrolyte Physiol. 27):F1110-F1124 (1990).

60 D. J. Marsh and C. M. Martin, Lack of water or urea movement from pelvic urine to papilla in hydropenic hamsters, Mineral and Electrolyte Metabolism 3:81-86 (1980).

61 A. Rocha and J. P. Kokko, Permeability of medullary nephron segments to urea and water: Effect of vasopressin, Kidney Internat. 6:379-387 (1974).

62 W. Kriz, Structural organization of the renal medullary counterflow system, Fed. Proc. 42:2379-2385 (1983).

63 K. V. Lemley and W. Kriz, Cycles and separations: The histotopography of the urinary concentrating process, Kidney Internat. 31:538-548 (1987). 